\title{
Alerts for policy makers extracted from papers published during 2016 in volume 8 of food security
}

\author{
Richard Strange ${ }^{1}$
}

Published online: 30 December 2016

(C) Springer Science+Business Media Dordrecht and International Society for Plant Pathology 2016

This item summarizes very briefly some of the papers published in volume 8 of Food Security for the year 2016, drawing attention to current and future critical issues in food and nutrition insecurity and measures that could be adopted to ameliorate them. It is perhaps worth mentioning that many are context specific, requiring detailed information. This implies far more work on the ground - in two words, extension officers. These should be well trained in the recognition of those factors that are preventing the attainment of reasonable yields of crop plants and proper development of humans: for the former, professionals should include agronomists and plant pathologists and for the latter nutritionists. It is hoped that Policy Makers concerned with food and nutrition security will note the papers relevant to their particular sphere of influence and that they will be inspired to take early action. Numbers after each entry refer to the pages on which the papers may be found in Volume 8 of the journal.

\section{The biological environment: productivity and constraints}

\section{Food production}

1. The effects of technology adoption on food security: James Sumberg's opinion piece is a warning of the perils of applying sophisticated models to unsophisticated data concerning technology adoption. He makes a plea for new investment in 'data collection that is sensitive to the non-

Richard Strange

r.strange@ucl.ac.uk

1 University College London, Gower Street, London WC1E 6BT, UK binary, non-linear, socially-embedded processes and dynamics of technological change' (pp 1037-1038)

2. Seed systems (1): Shawn McGuire and Louise Sperling show that all seed sectors have to be strengthened in order to catalyze smallholder advances. These include increased production, nutritional gains and the fostering of farming system resilience (pp 179-125)

3. Seed systems (2) Tomonori Yokouchi and Kazuki Saito point out the vital role of extension services in the adoption of NERICA rice (New Rice for Africa) and show that it favoured gender equality. They advocate the enhancement of farmer-to-farmer seed exchange (197-209).

4. Alleviating seasonal hunger in northwest Bangladesh: Florencia Palis and associates found that adoption of short duration rice and its direct seeding mitigated or even eradicated the monga (hunger) season in northwest Bangladesh (pp 443-457)

Fish

1. Culture based fisheries to augment food security in Asia: Sena de Silva points out that in Asia there are nearly 67 million hectares of small water bodies that are ideal for culture based fisheries. The production of fish from this source could do much to alleviate the shortfall in food fish anticipated for 2050 (pp 585-596)

Insects

1. Entomophagy - the consumption of insects in Benin: This topic was studied by Laura Riggi and associates, who identified 29 arthropod species that were consumed. They make an urgent plea that local traditions and knowledge of 
these species should be capitalised on before it is lost and that, in the light of considerable malnutrition in the country among young children, entomophagy should be promoted pp. 139-149)

2. Role of the Mopane worm in household food security in Limpopo province, South Africa: In this specific example of entomophagy, Lloyd Baiyeguhi and associates found that the Mopane worm (caterpillar of the Emperor Moth Embrasia belina) played a significant role in the food security of the indigenous population, necessitating the conservation of its woodland habitat and suggesting promotion of its consumption and commercialisation (pp 153-165)

\section{Pests, diseases and their control}

1. Plant health and food security, linking economics, policy and industry: Eleven papers arising from a conference with this title include exclusion, quarantine, eradication and control strategies (pp 17-121)

2. Pest-resistant maize: Tadele Tefera and associates discuss the performance of several high yielding hybrid and openpollinated maize varieties, developed and deployed by CIMMYT and its partners, which are resistant to devastating stem borers and post-harvest insect pests (pp 211-220)

3 . Control of post harvest pests of maize with low permeability triple-layer plastic bags: Jeremiah Ng'ang'a and associates report highly successful results from experiments on storing shelled maize in Purdue Improved Crop Storage $\left(\mathrm{PICS}^{\mathrm{tm}}\right)$ bags, which are suitable for onfarm storage in rural areas. Maize was free from infestation and weight loss was less than 1\% (pp 621-633)

4. Genetic modification for disease resistance: Peter Scott and associates point out the potential benefits of GM technology for conferring disease resistance in plants but in some cases the use of this powerful technique has been held up by regulation or the lack of it (865-870)

5. Xanthomonas wilt of Bananas: Mpoki Shimweal and associates report that this devastating disease of a staple crop continues to spread despite a campaign to remove symptomatic plants. They recommend that plant removal should be confined to dry periods and farm tools should be sterilized by fire (939-951)
The socio-economic and political environment

\section{Nutrition and food security}

1. Improved maize varieties reduce the probability of stunting: Julius Manda and associates found that the adoption of improved maize varieties reduced the probability of stunting by about $26 \%$ in the Eastern Province of Zambia (pp 239-253)

2. Nutrition transition for pastoralists: Göran Bostedt and associates show that agroforestry combined with knowledge provided by extension services could provide pastoralists with a transition path to improved dietary diversity (pp 271-284)

3. Coupling nutrition and food security with soil regeneration: Steven Vanek and associates found that better child nutrition and feeding practices were associated in some households with farming practices that sustain soils and secure higher yields per unit area (727-742)

4. Developing a nutrition-sensitive agriculture intervention: Peter Berti and associates describe a multi-site experience in which a framework of nutritionsensitive interventions which stood a reasonable chance of success were implemented in two settings in upland Vietnam and one setting in Thailand (pp 1053-1068)

5. Extension strategies for increasing the adoption of biofortified crops: Hugo de Groote and associates, using the example of quality protein maize in East Africa, found that for biofortified crops to be adopted, their agronomic properties should be equal or superior to conventional varieties (1101-1122)

Economic events and policies in relation to food insecurity

1. Vulnerability of food security to trade in developing countries: C. Laroche-Dupraz and M. HuchetBourdon hypothesized that the Bonilla Index (the ratio of national food import expenditures to the total value of exports) is an indicator of vulnerability to food insecurity. Using the index they showed that Developing Countries used variation in their rate of nominal assistance to compensate for the surge in food prices in 2008 (pp1191-1206) 